Results: We included 73 RA patients witch mean age of $52.7+/-11.7$, their mean of body mass index was $26.6+/ 5.8$, mean of disease activity score was $2.6+/-0.94$ and the mean health assessment questionnaire was $1.14+/ 0.78$. In univariable linear regression, we found a significant association between femoral BMD and (BFM) ( $p=0.001$, béta=0.36, IC:[0.000003-0.00001]), (AFM) $(p=0.01$, béta $=0.29, I C:[0.00001,0.00008])$ and (GFM) $(p=0.001$, béta $=0.38$, $\mathrm{IC}=[0.000005-0.000088])$. There wasn't any association between (VFM) and femoral BMD. Also we have found a significant association between lumbar spine BMD and BFM ( $p=0.0002$, béta $=0.41, I C[0.000003-0.000011]), A F M(p=0.001$, béta $=0.38$, IC[0.000025-0.000094]), GFM( $\mathrm{p}=0.000018$, béta $=0.47$, IC[0.00003$0.00007]$ and VFM $(p=0.01$, béta $=0.28, I C[0.000027,0.000251])$. Adjusted on BFM, GFM, AFM and VFM in multiple regression analysis, it seems that the association between GFM, femoral BMD $(p=0.02$, béta $=0.38, I C[0.000005$, $0.000088]$. and lumbar spine $\operatorname{BMD}(p=0.01$, béta $=0.85, I C[0.000022,0.000168])$, was more significant.

Conclusion: The finding of this study confirmed previous studies partly, that genoid fat mass has a positive effect of lumbar and femoral BMD.

References: [1]S. Yang et al. Association between fat mass, lean mass, and bone loss: the Dubbo osteoporosis epidemiology study. International Osteoporosis Foundation and National Osteoporosis Foundation 2014, osteoporosis int. 2015; 26(4): 1381-6.

Disclosure of Interests: None declared

DOI: 10.1136/annrheumdis-2020-eular.4648

\section{AB0253 A REVIEW OF SMOKING CESSATION STRATEGIES AND LUNG CANCER SCREENING PRACTICES IN PATIENTS WITH RHEUMATOID ARTHRITIS}

M. A. Lopez-Olivo ${ }^{1}$, R. Volk ${ }^{1}$, K. J. Krause ${ }^{2}$, M. Suarez-Almazor ${ }^{1} .{ }^{1}$ The University of Texas, MD Anderson Cancer Center, Health Services Research, Houston, United States of America; ${ }^{2}$ The University of Texas, MD Anderson Cancer Center, Research Medical Library, Houston, United States of America

Background: Smoking rates among patients with rheumatoid arthritis (RA) exceed those reported in the general population. In addition, people with RA who smoke are more likely to develop lung cancer than smokers who do not have RA Objectives: To identify smoking cessation strategies and lung cancer screening practices in patients with $\mathrm{RA}$.

Methods: We conducted a review of the literature in electronic databases (i.e. PubMed, EMBASE, Cochrane, Scopus, and Web of Science) from inception until June 2019. We included studies that reported on the results of interventions for smoking cessation or lung cancer screening in patients with RA. We excluded case reports, reviews, guidelines, protocols, or studies on tobacco use not reporting interventions. We included studies published in abstract or full-text format. We extracted study and intervention characteristics including delivery format, timing and results.

Results: We retrieved 394 relevant citations and ultimately included 9 studies evaluating smoking cessation strategies, and one regarding lung cancer screening practices. Five studies were reported in abstract format. There were 3 studies conducted in the United Kingdom, and one each in Croatia, France, Ireland, New Zealand, Sweden, Spain and United States. Two studies were randomized control trials and the remaining were uncontrolled. Follow-up ranged between 1 month and 24 months, however, one study only reported data on the assessment immediately after the intervention. Sample sizes ranged between 20 and 185 current smokers. Smoking cessation strategies included: 1) brief advice and nicotine replacement therapy + smoking cessation counseling for 3 months; 2) information booklet on harms of smoking (i.e., impact on disease and treatment); 3) spoken information on harms of smoking (i.e., impact on disease and treatment) plus advice to quit smoking; 4) advice to quit smoking plus nicotine replacement; 5) smoking cessation support with contact every 4 weeks; 6) spoken information on harms of smoking (i.e., impact on disease and treatment) plus advice to quit smoking plus nurse telephone visit at $3^{\text {rd }}$ month; 6) staff driven tobacco QUIT line referral process; 7) multi-modality intervention with advise to quit smoking plus guidance on safe alcohol use plus dietary advise with booklet and swimming group. The lung cancer screening study reported on a program with nurse evaluation of comorbidities and risk factors, and recommendations for lung cancer screening with a chest $\mathrm{X}$-ray and smoking cessation. Most studies reported benefits when implementing a structured plan to educate, counsel, and offer pharmacological treatment to patients with RA.

Conclusion: There was large heterogeneity among studies in patient characteristics and interventions proposed, and outcomes. Only 2 studies were randomized clinical trials. Additional controlled studies are needed to determine best practices for smoking cessation and lung cancer screening in patients with RA. Disclosure of Interests: None declared

DOI: 10.1136/annrheumdis-2020-eular.4751

\section{AB0254 PATIENT CHARACTERISTICS, COMORBIDITIES, AND INFECTION OUTCOMES AMONG RHEUMATOID ARTHRITIS (RA) PATIENTS IN PUERTO RICO (PR)}

M. Suryavanshi ${ }^{1}$, S. Suri ${ }^{2}$, Y. Bao ${ }^{1}$, M. Ruiz ${ }^{3}$, V. Patel ${ }^{1}$, E. Madera-Miranda ${ }^{3}$. ${ }^{1}$ Bristol Myers Squibb, NJ, United States of America; ${ }^{2}$ Mu Sigma, Karnataka, India; ${ }^{3}$ Bristol Myers Squibb, Guaynabo, Puerto Rico

Background: Although the burden of comorbidities and infections in RA patients in the US is well established, ${ }^{1}$ there is an evidence gap for RA patients in the US territory of PR.

Objectives: To describe the patient demographics, clinical characteristics, and infection rates in patients with RA in $\mathrm{PR}$

Methods: $A$ retrospective cohort of adults age $\geq 18$ years from $P R$ with $\geq 2$ diagnosis of RA were identified using International Classification of disease codes (ICD-9 or ICD-10) on separate days from Jan 1, 2006 to June 30, 2018 using the Truven MarketScan $^{\mathrm{TM}}$ database. Patients were divided into three treatment cohorts: no treatment, conventional disease-modifying anti-rheumatic drugs (csDMARD) user and biologic DMARD (bDMARD) user. Patients in the no treatment group were followed from their first RA diagnosis date to the date of initiation of any DMARDs. The csDMARD users were followed from the initiation of csDMARD until the initiation of any bDMARD or targeted synthetic DMARDs (tsDMARDs). Patients were censored at the last observed medical claim if treatments were not initiated during follow-up. bDMARD users were followed from the date of initiation of bDMARD or tsDMARD until their last observed medical claim. Crude incidence rates /1000 person-years (PY) were reported for opportunistic infections (e.g. Mycobacterium, Cytomeglavirus, Candidiasis, and Chlamydial infections) and infections requiring hospitalisation. Results: Of the 623 patients in the cohort of RA patients from PR, majority were women $(75.4 \%)$, aged $41-64$ years $(67.1 \%)$, employed full time $(69.8 \%)$, with PPO health plan (89.4\%), and with mean length of follow-up of 5.77 years from index RA diagnosis. Our results shows that cardiovascular conditions (CVD, hypertension, and hyperlipidemia) were the most prevalent comorbidities in PR patients with RA (Table 1), followed by diabetes $(55.7 \%$ ) in the total RA patient population. The crude IR/1000 PY for opportunistic infections was 23.35 for patients in the no treatment cohort, 48.52 for patients in csDMARD, and 28.31 for bDMARD users. For hospitalized infections, the crude IR/1000 PY was 26.00 for patients in the no treatment cohort, 22.08 for csDMARD users, and 41.90 for bDMARD users.

Table 1. Patient Clinical Characteristics

\begin{tabular}{|c|c|c|c|c|c|c|c|c|}
\hline Patient Characteristics & $\begin{array}{l}\text { Total } \\
\text { Patients }\end{array}$ & & $\begin{array}{l}\text { No } \\
\text { Treatment }\end{array}$ & & $\begin{array}{l}\text { csDMARD } \\
\text { user }\end{array}$ & & $\begin{array}{l}\text { DMARD } \\
\text { ser }\end{array}$ & \\
\hline & $\mathrm{N}$ & $\%$ & $\mathrm{~N}$ & $\%$ & $\mathrm{~N}$ & $\%$ & $\mathrm{~N}$ & $\%$ \\
\hline \multicolumn{9}{|l|}{$\mathrm{CCl}$ Score } \\
\hline Mean (SD) & $\begin{array}{c}2.31 \\
(1.85)\end{array}$ & & $\begin{array}{c}2.39 \\
(1.82)\end{array}$ & & $1.85(1.47)$ & & $\begin{array}{c}2.57 \\
(2.41)\end{array}$ & \\
\hline \multicolumn{9}{|l|}{ Comorbidities } \\
\hline Total Patients & 571 & $91.7 \%$ & 486 & $80.2 \%$ & 130 & $77.4 \%$ & 76 & $80.9 \%$ \\
\hline Asthma & 170 & $29.8 \%$ & 125 & $25.7 \%$ & 33 & $25.4 \%$ & 25 & $32.9 \%$ \\
\hline Chronic Kidney Disease & 47 & $8.2 \%$ & 32 & $6.6 \%$ & 7 & $5.4 \%$ & 8 & $10.5 \%$ \\
\hline COPD & 138 & $24.2 \%$ & 108 & $22.2 \%$ & 22 & $16.9 \%$ & 16 & $21.1 \%$ \\
\hline Cardiovascular disease & 357 & $62.5 \%$ & 278 & $57.2 \%$ & 61 & $46.9 \%$ & 55 & $72.4 \%$ \\
\hline Hypertension & 447 & $78.3 \%$ & 371 & $76.3 \%$ & 87 & $66.9 \%$ & 63 & $82.9 \%$ \\
\hline Hyperlipidemia & 418 & $73.2 \%$ & 350 & $72.0 \%$ & 66 & $50.8 \%$ & 47 & $61.8 \%$ \\
\hline Malignancy & 124 & $21.7 \%$ & 101 & $20.8 \%$ & 18 & $13.9 \%$ & 20 & $26.3 \%$ \\
\hline Peripheral artery disease & 74 & $13 \%$ & 58 & $11.9 \%$ & 10 & $7.7 \%$ & 11 & $14.5 \%$ \\
\hline T2DM & 318 & $55.7 \%$ & 251 & $51.7 \%$ & 58 & $44.6 \%$ & 37 & $48.7 \%$ \\
\hline
\end{tabular}

Note: Comorbidities and $\mathrm{CCl}$ was calculated for patients during follow-up in respective cohort

Conclusion: Puerto Rican patients with RA have a significant burden of comorbidities, infections and hospitalisations. Trends indicate a variation in the burden by the type of treatment. Furthermore studies are warranted to better understand the potential healthcare implications of comorbidities in patients with RA.

References: [1]Yun, Huifeng et al. "Comparative risk of hospitalised infection associated with biologic agents in rheumatoid arthritis patients enrolled in Medicare." Arthritis \& Rheumatology 68, no. 1 (2016): 56-66.

Disclosure of Interests: Manasi Suryavanshi Consultant of: Bristol Myers Squibb, Sonick Suri Consultant of: Bristol Myers Squibb, Ying Bao Shareholder of: Bristol-Myers Squibb, Employee of: Bristol-Myers Squibb, Maribelis Ruiz Shareholder of: Bristol Myers Squibb, Employee of: Bristol Myers Squibb, Vardhaman PATEL Employee of: Bristol Myers Squibb, Eory Madera-Miranda Employee of: Bristol Myers Squibb

DOI: 10.1136/annrheumdis-2020-eular.3730 